\begin{tabular}{|c|c|c|c|}
\hline$\Omega$ & (1] & $\equiv$ & (2) \\
\hline Elisabeth Quoix & $\begin{array}{l}\text { University of Strasbourg, } \\
\text { Chest Disease Department, } \\
\text { University Hospital, } \\
\text { Strasbourg, France }\end{array}$ & $\begin{array}{l}\text { University of Strasbourg, } \\
\text { Chest Disease department, } \\
\text { University Hospital, 1 place } \\
\text { de l'hôpital, } 67091 \\
\text { Strasbourg cedex, France }\end{array}$ & elisabeth.quoix@chru-strasbourg.fr \\
\hline
\end{tabular}

\title{
Advanced non-small cell lung cancer in elderly patients
}

This article aims to provide guidelines in the management of elderly patients with advanced non-small cell lung cancer. Epidemiology of lung cancer shows the considerable increase in frequency of this disease in elderly people, with a median age at diagnosis between 63 and 70 years. Thus, there is a need for a specific and appropriate approach. Studies dedicated to elderly patients are the only means to avoid selection biases which are inherent to the studies enrolling patients of any age in clinical trials. These biases preclude any generalisability of the results observed in subgroup analyses of elderly patients. Geriatric assessment is an important component of the management of elderly patients, as performance status (PS) has been shown to be insufficient to estimate accurately the general condition of these patients.

Lung cancer is the second most common cancer in males, after prostate cancer, and the third in females after breast and colorectal cancer. Also it is the leading cause of cancer-related death in males from developed or emerging countries [1] and in females in the USA since 1987, exceeding breast cancer mortality [2]. There is an exponential increase in cancer incidence with ageing and, due to the concomitant increase of life expectancy, the incidence of lung cancer in the elderly is more and more important, representing a public health problem in developed countries in which life expectancy is important. As a result, the median age of diagnosis of lung cancer ("clinical" diagnosis, histological/cytological or both) in industrialised nations is 63 to 70 years [3-7]. Non-small cell lung carcinoma (NSCLC) represents $85 \%$ of all lung cancer cases in the elderly [8-10]. This is quite similar to what is observed in their younger counterparts. However, within NSCLC, squamous cell carcinomas are more frequent in the elderly compared with younger patients, in whom adenocarcinoma is now the main subtype [8-10]. There are also more neversmokers in elderly patients compared with younger patients and this is probably due to the fact that ageing is an important risk factor; within a recent French survey of 1,627 lung cancer patients aged $\geqslant 70$ years, neversmokers represented $4 \%$ of $70-74$ year olds, $13.4 \%$ of $75-79$ year olds and $18.7 \%$ of those aged $\geqslant 80$ [10].

Elderly people are under-represented in clinical trials $[7,11,12]$ and also may not receive appropriate treatment, possibly due to the pessimism of the doctors, patients and their relatives regarding treatment relevance and toxicity in elderly patients [12].

In population-based studies, elderly patients are not offered chemotherapy in a large majority of cases. For example, in the recently published SEER database [13], only $25.8 \%$ of the 21,285 patients aged $>65$ years diagnosed with NSCLC between 1997 and 2002 received first-line chemotherapy. In a recent analysis of the Manitoba registry [14], only 82 patients, $16.5 \%$ of the 497 patients aged $>70$ years,
Statement of interest None declared.

HERMES syllabus link: module B.2.1 
were offered chemotherapy. Alternatively, in the aforementioned French prospective hospitalbased survey of 1,627 patients, $60 \%$ received some kind of chemotherapy [10].

As a matter of fact, elderly patients differ from their younger counterparts in many respects. First, they usually display many more comorbidities, especially those linked to tobacco use (coronary disease, obliterans arteritis of lower limbs, hypertension, chronic obstructive pulmonary disease (COPD), etc.), all of which may compromise the administration of chemotherapeutic agents, for example cisplatin in the case of cardiac insufficiency or severe COPD, which do not allow hyperhydration.

Secondly, due to the number of comorbidities, elderly patients may take quite a number of medications, and special attention should be paid as they may interfere with the metabolism of chemotherapeutic drugs. Moreover, quite a number of these patients take selfprescribed drugs, which are sometimes inappropriate and not reported to their doctor [15].

Thirdly, with ageing, physiological functions decline, such as renal function and haematopoiesis. Finally, geriatric syndromes are also increasingly common with age, resulting in a potential vulnerability and frailty among this patient population. It is therefore of paramount importance to take into account comorbidities, pharmacodynamics of cancer drugs and geriatric assessment prior to the decision-making process for cancer treatment.

\section{Comorbidities and polypharmacy}

Comorbidities may be assessed using the Charlson comorbidity scale [16] (see box) or the cumulative illness rating scale geriatric (CIRS-G) (see box) both of which have been validated [17]. Although comorbidity is defined in a more restrictive way as measured by Charlson's index and in a comprehensive way as assessed using CIRS-G, there is no indication that one is more useful than the other in clinical trials carried out on elderly patients. PS may be modified by comorbidities but they are not well correlated and should thus be addressed separately [17-19]. Careful checking of all drugs taken by elderly patients should be done before any decision especially regarding chemotherapy. In fact, elderly patients with metastatic cancer have been reported to take a median of 5-7 concomitant medications not taking into account the "over the counter" drugs and alternative or herbal remedies [15]. Contrary to general belief, alternative remedies may interact not only with chemotherapy but also with the other drugs taken before cancer treatment is initiated, such as antihypertensives, lipidlowering, anti-platelets or anticoagulants, inducing additional toxicity.

Regarding lung cancer, there may be interaction between carboplatine, gemcitabine, paclitaxel or etoposide and warfarin (increased anticoagulant effect), between cisplatin and phenytoin with a reduced control of seizures but also with erlotinib or gefitinib with phenytoin,

\section{Charlson comorbidity scale [I6]}

\begin{tabular}{lc} 
Comorbidity & Score \\
Myocardial infarct & 1 \\
Congestive heart failure & 1 \\
Peripheral vascular disease & 1 \\
Dementia & 1 \\
Cerebrovascular disease & 1 \\
Chronic lung disease & 1 \\
Connective tissue disease & 1 \\
Ulcer & 1 \\
Chronic liver disease & 1 \\
Hemiplegia & 2 \\
Moderate or severe kidney disease & 2 \\
Diabetes & 2 \\
Diabetes with complication & 2 \\
Tumour & 2 \\
Leukaemia & 2 \\
Lymphoma & 2 \\
Moderate or severe liver disease & 3 \\
Malignant tumour & 6 \\
Metastasis & 6 \\
AlDS & 6 \\
\hline Comoridit scores are summed & \\
\hline
\end{tabular}

Comorbidity scores are summed and the total score predicts 10-year mortality. For each decade of age $>40$ years, a score of 1 is added to the total. 
Cumulative illness rating scale geriatric (CIRS-G)

Severity
No problem
Current mild problem or
past significant problem
Moderate disability or morbidity/
requires "first line" therapy
Severe/constant significant disability/
"uncontrollable" chronic problems
Extremely severe/immediate
treatment required/end organ
failure/severe impairment
in function
Each of 14 organ/biological systems is
evaluated and the score totalled to give a
cumulative score indicative of severity of
comorbidities.

carbamazepine and primidone with a reduced activity of those targeted therapies.

\section{Physiological alterations of functions with ageing}

These are of special importance regarding renal and haematopoietic functions. These modifications may explain an increased chemotherapy toxicity [20, 21] which must be taken into account. Drugs with renal metabolism or high level of haematotoxicity should have their dosage adjusted properly. Renal function must be carefully considered if cisplatin is to be used. One must remember that although the outcome with carboplatin is slightly inferior to cisplatin in advanced NSCLC [22], it is easier to use it especially in elderly patients because the dosage is adapted to renal function and because it does not require hyperhydration which is somewhat difficult in elderly patients who may have cardiac problems.

Haematological toxicity is anticipated to be more severe in elderly patients. However, growth factors appear to have the same efficacy as in younger patients and should be considered [23]. Primary prophylaxis with granulocyte colony-stimulating factor (G-CSF) is of special interest as the highest incidence of toxicities which could result in the patient's death occurring during the first cycle of chemotherapy especially in small cell lung cancer [20]. Although this has been especially demonstrated in elderly patients treated for a nonHodgkin lymphoma, prophylactic use of G-CSF should reduce, in the same way, the risk of neutropenia in elderly patients with advanced non-small cell lung cancer when they are treated with myelotoxic drugs. A recent study evaluated in elderly patients with advanced non-small cell lung cancer the adjunction of levofloxacin versus placebo to chemotherapy with carboplatine plus docetaxel [24]. The infection rates were lower in the prophylactic antibiotherapy group.

\section{Geriatric assessment}

PS, even though it is an important prognostic factor in younger patients, cannot by itself predict outcome in elderly patients [17] making it mandatory to perform a geriatric assessment [25]. This geriatric assessment comprises several items (table 1 ) addressing cognition (mini-mental score [26]), daily activities (activity of daily living (ADL), instrumental ADL (IADL) [27]), depression, which is too often underestimated in elderly patients (geriatric depression scale [28]), nutrition [29], physical performance ("get up and go" test) and geriatric syndromes. The ADL checklist includes everything necessary for self-care (dressing, transferring, feeding, toilet, etc.). IADLs refer to the use of transportation, the utilisation of the telephone, the ability to go shopping, proper medication intake and money management, etc. The timed get-up-and-go test is the time required to get up from a chair, walk 3 metres and return back to the chair. All these evaluations are part of the comprehensive geriatric assessment (CGA), which is a highly time-consuming procedure. Screening tests have been developed in order to select patients who should really undergo a complete CGA [30].

After careful geriatric assessment, elderly patients may be classified into three groups according to Balducci (fig. 1) [31] First group: patients with no specific risk and who may be treated like their younger counterparts. Second group: patients who have treatable comorbidities and may be treated with an adapted treatment. Third group: patients who have multiple untreatable comorbidities or for dependent patients, only best supportive care should be proposed. 
Table 1. Comprehensive geriatric assessment

\section{Parameters}

Assessment methods

\begin{tabular}{ll}
\hline Functional status & PS, ADL, IADL, timed get-up-and-go test \\
\hline Comorbidities & Charlson comorbidity index, CIRS-G \\
\hline Socio-economic status & $\begin{array}{l}\text { Income, transportation possibilities, living } \\
\text { conditions, somebody helping }\end{array}$ \\
\hline Cognitive status & Folstein mini-mental score \\
\hline
\end{tabular}

\begin{tabular}{ll}
\hline Nutritional status & Body mass index, nutritional mini-questionnaire \\
\hline Emotional status & Depression geriatric scale \\
\hline Medications & Number, usefulness, interactions \\
\hline
\end{tabular}

Geriatric syndromes

Dementia, repeated falls, bone fractures, neglecting, abuse

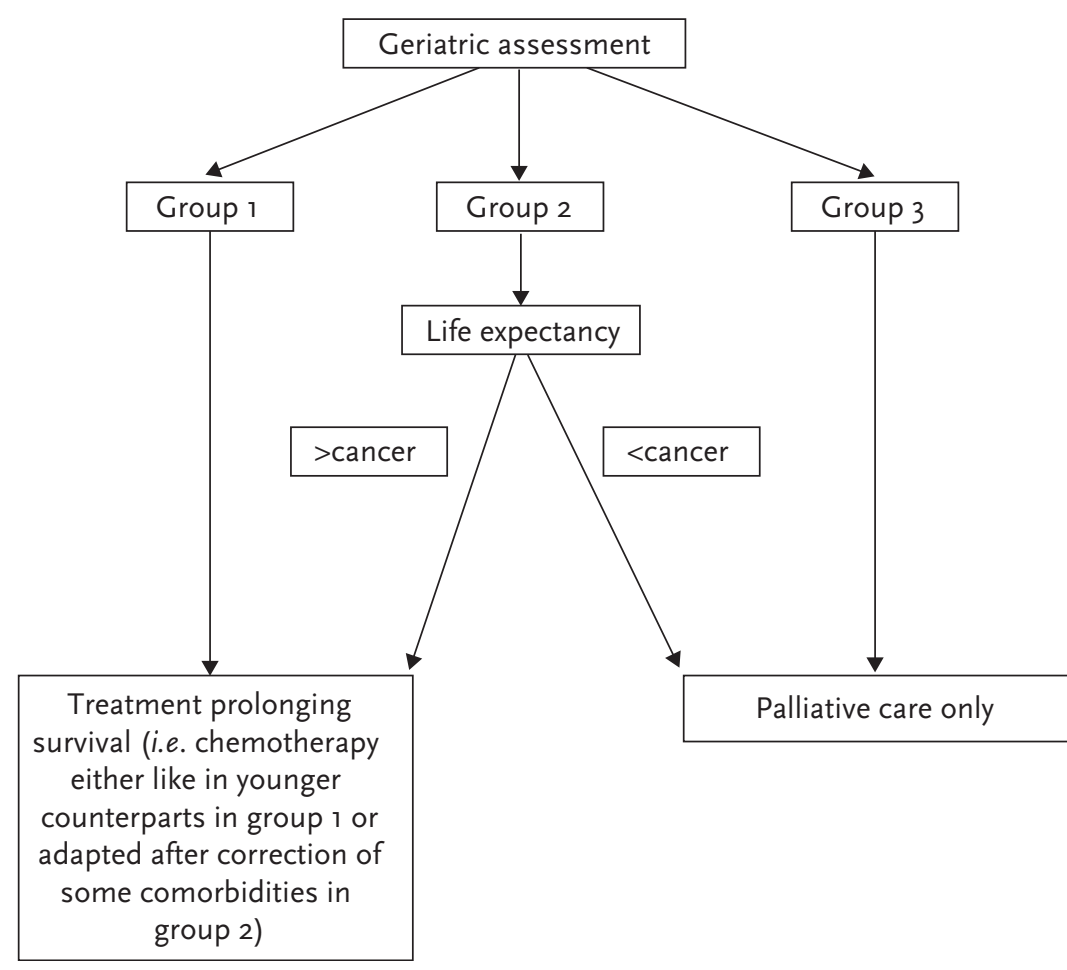

Figure 1

The three Balcucci groups. > cancer: life expectancy better than that with cancer; $<$ cancer: life expectancy worse than that with cancer.

\section{Treatment of elderly patients with advanced non-small cell lung cancer not amenable to mediastinal radiation therapy or at a metastatic stage}

Treatment recommendations for fit patients (PS O-1) with advanced non-small cell lung cancer are to administer a platinum salt-based doublet, the second drug being vinorelbine, gemcitabine, taxotere, paclitaxel or pemetrexed $[32,33]$. Until the 1990s, there were no specific trials dedicated to elderly patients. As a result, no recommendations could be established for a long time and most of these patients were undertreated.

There are two approaches toward the treatment of elderly patients: first to include them in clinical trials not dedicated specifically to the elderly (i.e. trials with no age limits), and secondly to build trials devoted to elderly patients. In the first case, there is obviously a selection bias as those patients included in clinical trials with treatment adapted to younger patients are highly selected and are not representative. Also, the median age of the elderly patients enrolled in these studies is not very high as most of time older elderly people are not represented. For example, in a clinical trial using cisplatin-based doublet, very few patients aged above 75 years will be included. Thus, there is no generalisability of the results to the entire population of elderly patients. In the second case, the difficulty is to determine an age cutoff. Usually, there is no need to adapt treatment before 70 years and thus most of the trials dedicated to elderly patients include those aged $\geqslant 70$ years.

Non-specific trials performed with subgroup analyses of elderly patients [34-38] are displayed in table 2. With the exception of the combined results of two Southwest Oncology Group trials reported by BLANCHARD et al. [38], these studies did not show any significant difference in survival between patients aged $<70$ years and those aged $>70$ years (the cutoff was 65 years in BeLANI and FosselLa [36]).

The first randomised study dedicated to elderly patients was performed by the ELVIS Group, and published in 1999 [39]. This trial compared vinorelbine alone to best supportive care in 154 patients aged $\geqslant 70$ years and more 
Table 2. Subgroup analyses of patients aged $\geqslant 70$ years in non-specific clinical trials

\begin{tabular}{|c|c|c|c|c|c|}
\hline LANGER (2002) & $574 / 86$ & $\begin{array}{l}\text { CDDP + VP16 versus } \\
\text { CDDP + Pacli }\end{array}$ & $21.5 / 23.3^{\#}$ & $9.1^{\#} / 8.5$ & $38^{\# / 29}$ \\
\hline BELANI (2005) & $1218 / 401^{\circ}$ & $\begin{array}{l}\text { CDDP + Doc versus } \\
\text { Carbo + Doc versus } \\
\text { CDDP + VNR }\end{array}$ & & $\begin{array}{c}11.0 / 12.6 \\
9.7 / 9 \\
10.1 / 9.9\end{array}$ & $\begin{array}{l}44 / 52 \\
37 / 39 \\
41 / 41\end{array}$ \\
\hline BLANCHARD (2011) & $616 / 122$ & $\begin{array}{l}\text { CDDP + VNR versus } \\
\text { Carbo + Pacli }\end{array}$ & $27 / 30$ & $9 / 7(p=0.04)$ & $40 / 27$ \\
\hline
\end{tabular}

with advanced-non-small cell lung cancer. Survival benefit in the single agent chemotherapy arm was highly significant (median survival time 28 versus 21 weeks and 1-year probability of survival 32 versus $14 \%$ ). After this trial demonstrating the benefit of chemotherapy in elderly patients with advancednon-small cell lung cancer, two other studies compared single agent chemotherapy versus a non-platinum based doublet, i.e. vinorelbine and/or gemcitabine alone versus vinorelbine and gemcitabine. The first of these two trials published by FrASCl et al. [40] included only 120 patients and showed a benefit of survival in the doublet arm. However, a much larger trial including 700 patients [41] was unable to demonstrate any benefit of survival in the doublet arm. Owing to the results of these studies the recommendations for elderly patients with advanced non-small cell lung cancer were to treat them with a single agent therapy [42], the most frequently investigated being vinorelbine and gemcitabine.

In a Japanese study, vinorelbine was compared with docetaxel [43]. Response rate was significantly higher and progression-free survival was significantly longer in the docetaxel arm. There was also a trend toward a longer survival but this was not significant. The first study comparing a single agent therapy (docetaxel) to a platin-based (carboplatine) plus docetaxel doublet was published as an abstract only and was prematurely closed after inclusion of 63 patients because of the demonstration in a pre-planned interim analysis superiority of the doublet in the 70-74 years category of age [44]. The second was published this year by the French Intergroup of Thoracic Oncology [45]. In this multicentric phase-III trial, 451 patients were included. This study compared a single agent therapy (vinorelbine $30 \mathrm{mg} \cdot \mathrm{m}^{-2}$ on day 1 and 8 , or gemcitabine $1,150 \mathrm{mg} \cdot \mathrm{m}^{-2}$ on day 1 and 8 every three weeks according to the initial choice of each centre) to the doublet carboplatine (AUC 6 every 4 weeks) plus paclitaxel $\left(90 \mathrm{mg} \cdot \mathrm{m}^{-2}\right.$ days 1,8 and 15 ). Five cycles of the single agent therapy and 4 cycles of the doublet were to be given in the absence of progression or toxicity. Median age was 77 years. Patients had either a stage-III not amenable to radiation therapy or a stage-IV disease and were included between April 2006 and December 2009. There was a significant increase in progression-free survival (6.1 versus 2.8 months) and a 4-month increase of median survival time (10.3 versus 6.2 months) in the doublet arm versus the monotherapy arm (fig. 2) with a 1-year probability of survival of 44.5 versus $24.5 \%$. Toxic deaths were more frequent in the doublet arm: $10(4.4 \%$ of the 


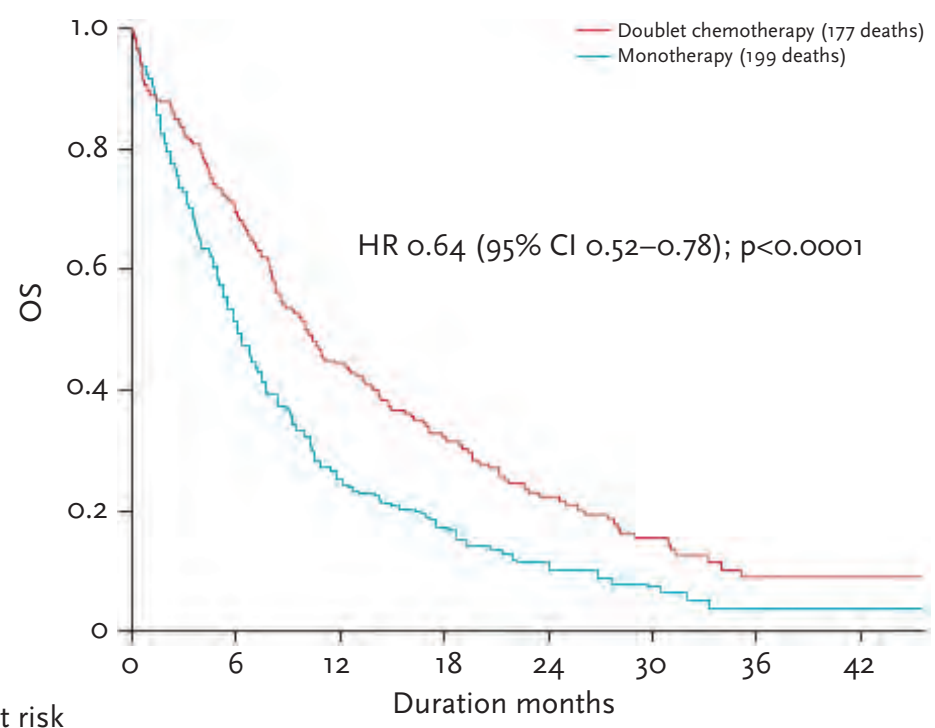

Number at risk

$\begin{array}{rrrrrrrrr}\text { Doublet } & 225 & 160 & 92 & 52 & 32 & 19 & 7 & 2 \\ \text { Monotherapy } & 226 & 117 & 54 & 25 & 15 & 8 & 2 & 2\end{array}$

\section{Figure 2}

Overall survival in the IFCT trial comparing a single agent therapy arm (vinorelbine or gemcitabine) and the doublet carboplatin plus weekly paclitaxel arm in patients aged $\geqslant 70$ years with advanced non-small cell lung cancer.

patients) versus three in the single agent arm ( $1.3 \%$ of the patients). Also, grade $3-4$ haematological toxicity was significantly more frequent in the doublet arm. This increased rate of toxic deaths and grade 3-4 haematological toxicity stress the fact that those elderly patients should be carefully monitored with this treatment. Despite the increase in toxic deaths, the rate of early death (within 3 months) was by far inferior in the doublet arm (16.4\%) compared with the single-agent arm (26.5\%).Moreover, in an exploratory analysis, it appeared that the benefit of carboplatin-based doublet was observed in all subgroups of patients even in those with bad prognostic factors (PS 2, patients aged $\geqslant 80$ years, patients with ADL $<6$, patients with a body mass index $<20$, etc.). The only variable not associated with a survival gain with the doublet was an MMS $<24$.

Thus, the results of this study suggest that monthly carboplatin plus weekly paclitaxel could be the standard treatment for elderly patients with PS O-2 and these results should modify the paradigm of the treatment of elderly patients with advanced non-small cell lung cancer.

\section{Conclusion}

Elderly patients with advanced non-small cell lung cancer should be treated by chemotherapy when PS is $\leqslant 2$. The carboplatin-based doublet provides survival gain compared

Table 3. Phase-III studies dedicated to elderly patients with advanced non-small cell lung cancer

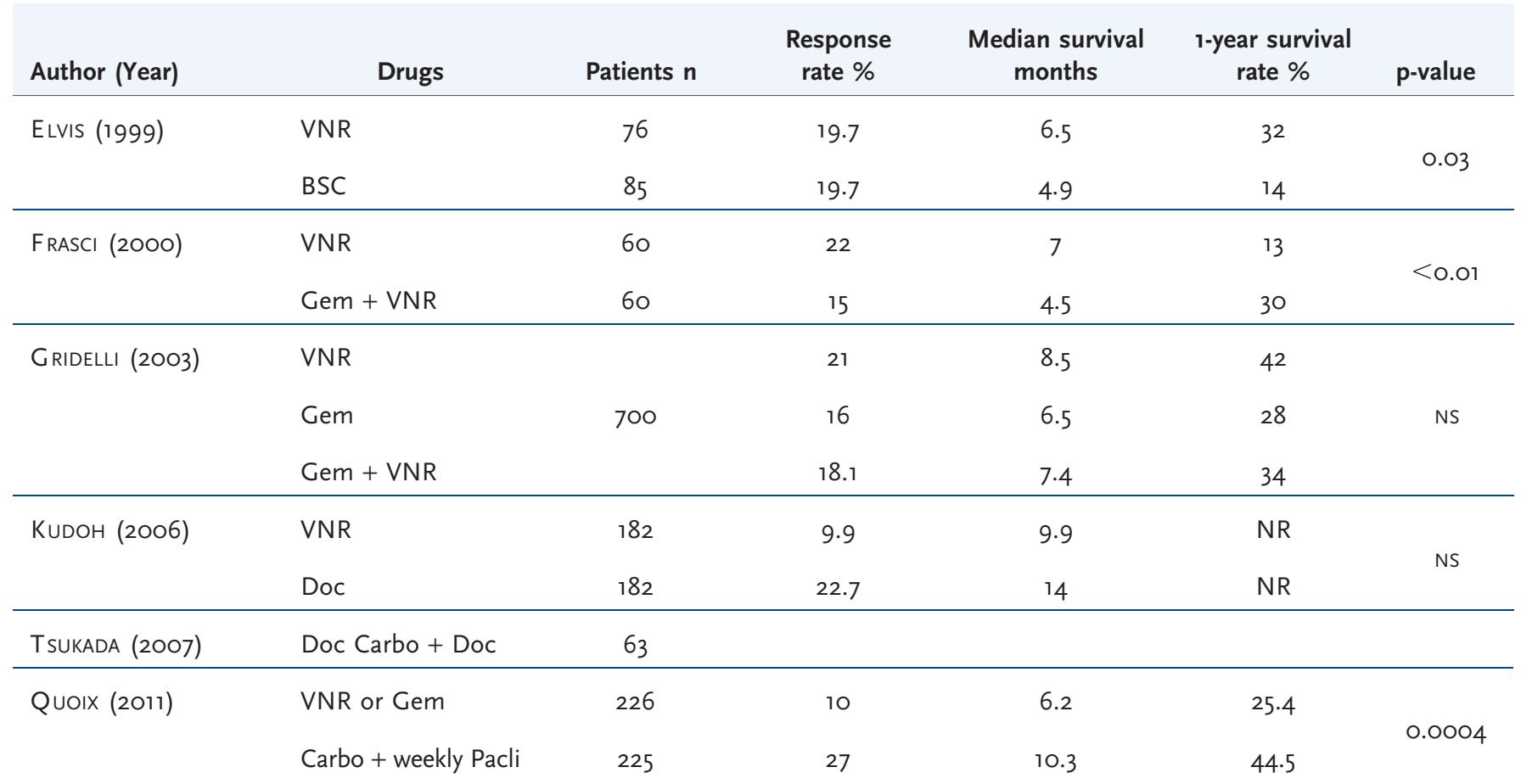


with a monotherapy in most subgroups of patients. Geriatric assessment may probably contribute to the choice between a monotherapy and carboplatine-based doublet testing procedures to discriminate between patients of group I who should be treated with a carboplatin-based doublet whereas, probably for group II, monotherapy should be discussed. Whether geriatric assessment is only a prognostic factor or predictive of the outcome of treatments remains to be determined. Anyway, nihilism is no more appropriate in the setting of elderly patients with advanced nonsmall cell lung cancer.

\section{References}

1. Parkin DM, Bray F, Ferlay J, et al. Global cancer statistics, 2002. CA Cancer J Clin 2005; 55: 74-108.

2. Baldini EH, Strauss GM. Women and lung cancer: waiting to exhale. Chest 1997; 112: Suppl. 4, 229S-234S.

3. Lebitasy MP, Hedelin G, Purohit A, et al. Progress in the management and outcome of small-cell lung cancer in a French region from 1981 to $1994 . \mathrm{Br} \mathrm{J}$ Cancer 2001; 85: 808-815.

4. Gregor A, Thomson CS, Brewster DH, et al. Management and survival of patients with lung cancer in Scotland diagnosed in 1995: results of a national population based study. Thorax 2001; 56: 212-217.

5. Foegle J, Hedelin G, Lebitasy MP, et al. Non-small-cell lung cancer in a French department, (1982-1997): management and outcome. Br J Cancer 2005; 92: 459-466.

6. Blanchon F, Grivaux M, Collon T, et al. [Epidemiologic of primary bronchial carcinoma management in the general French hospital centres.]. Rev Mal Respir 2002; 19: 727-734.

7. Jennens RR, Giles GG, Fox RM. Increasing underrepresentation of elderly patients with advanced colorectal or non-small-cell lung cancer in chemotherapy trials. Intern Med J 2006; 36: 216-220.

8. Owonikoko TK, Ragin CC, Belani CP, et al. Lung cancer in elderly patients: an analysis of the surveillance, epidemiology, and end results database. J Clin Oncol 2007; 25: 5570-5577.

9. Piquet J, Blanchon $\mathrm{F}$, Grivaux M, et al. [Primary lung cancer in elderly subjects in France.]. Rev Mal Respir 2004; 21: 8S70-8S78.

10. Quoix E, Monnet I, Scheid P, et al. [Management and outcome of French elderly patients with lung cancer: an IFCT survey.]. Rev Mal Respir 2010; 27: 421-430.

11. Yee KW, Pater JL, Pho L, et al. Enrollment of older patients in cancer treatment trials in Canada: why is age a barrier? J Clin Oncol 2003; 21: 1618-1623.

12. Hutchins LF, Unger JM, Crowley JJ, et al. Underrepresentation of patients 65 years of age or older in cancer-treatment trials. N Engl J Med 1999; 341: 2061-2067.

13. Davidoff AJ, Tang M, Seal B, et al. Chemotherapy and survival benefit in elderly patients with non-small-cell lung cancer. J Clin Oncol 2010; 28: 2191-2197.

14. Baunemann Ott CL, Ratna N, Prayag R, et al. Survival and treatment patterns in elderly patients with advanced non-small-cell lung cancer in Manitoba. Current Oncol 2011; 18: 238-242.

15. Lees J, Chan A. Polypharmacy in elderly patients with cancer: clinical implications and management. Lancet Oncol 2011; 12: 1249-1457.

16. Charlson ME, Pompei P, Ales KL, et al. A new method of classifying prognostic comorbidity in longitudinal studies: development and validation. J Chronic Dis 1987; 40: 373-383.

17. Extermann M, Overcash J, Lyman GH, et al. Comorbidity and functional status are independent in older cancer patients. J Clin Oncol 1998; 16: 1582-1587.

18. Extermann M. Geriatric oncology: an overview of progresses and challenges, 2010 Cancer Res Treat 2010; 42: 61-68.

19. Firat S, Byhardt RW, Gore E. The Effects of Comorbidity and Age on RTOG Study Enrollment in Stage III Non-Small Cell Lung Cancer Patients Who Are Eligible for RTOG Studies. Int J Radiat Oncol Biol Phys 2010; 78: 1394-1399.

20. Lichtman SM, Wildiers H, Launay-Vacher V, et al. (2007) International Society of Geriatric Oncology (SIOG) recommendations for the adjustment of dosing in elderly cancer patients with renal insufficiency. Eur J Cancer. 2007; 43: 14-34.

21. Shayne M, Culakova E, Poniewierski MS, et al. Dose intensity and hematologic toxicity in older cancer patients receiving systemic chemotherapy. Cancer 2007; 110: 1611-1620.

22. Ardizzoni A, Boni L, Tiseo M, et al. Cisplatin- versus carboplatin-based chemotherapy in first-line treatment of advanced non-small-cell lung cancer: an individual patient data meta-analysis. J Natl Cancer Inst 2007; 99: 847-857.

23. Repetto L, Biganzoli L, Koehne $\mathrm{CH}$, et al. EORT Cancer in the Elderly Task Force guidelines for the use of colony-stimulating factors in elderly patients with cancer. Eur J Cancer 2003; 39: 2264-2272.

24. Schuette W, Nagel S, von Welkersthal LF, et al. Randomized Phase III Trial of Docetaxel Plus Carboplatin with or without Levofloxacin Prophylaxis in Elderly Patients with Advanced Non-small Cell Lung Cancer: The APRONTA Trial. J Thorac Oncol 2011; 12: 2090-2096.

25. Repetto L, Fratino L, Audisio RA, et al. Comprehensive geriatric assessment adds information to Eastern Cooperative Oncology Group performance status in elderly cancer patients: an Italian Group for Geriatric Oncology Study. J Clin Oncol 2002; 20: 494C-502C.

26. Folstein MF, Folstein SE, McHugh PR. 'Mini-mental state': a practical method for grading the cognitive state of patients for the clinician. J Psychiatr Res 1975; 12: 189-198.

27. Katz S, Ford AB, Moskowitz RW, et al. Studies of Illness in the Aged. The Index of ADL: A Standardized Measure of Biological and Psychosocial Function. JAMA 1963; 185: 914-919.

28. Roose SP, Katz IR, Pollock BG, et al. Contemporary issues in the diagnosis and treatment of late-life depression. J Am Med Dir Assoc 2002; 3: $\mathrm{H}_{2} 6-\mathrm{H}_{2}$. 
29. Hardy C, Wallace C, Khansur T, et al. Nutrition, cancer, and aging: an annotated review. III. Cancer cachexia and aging. J Am Geriatr Soc 1986; 34: 219-228.

30. Extermann M. Geriatric oncology: an overview of progresses and challenges. Cancer Res Treat 2010; 42: 61-68.

31. Balducci L, Extermann M. Management of cancer in the older person: a practical approach. Oncologist 2000; 5: 224-237.

32. Hotta K, Matsuo K, Ueoka H, et al. Addition of platinum compounds to a new agent in patients with advanced non-small-cell lung cancer: a literature based meta-analysis of randomised trials. Ann Oncol 2004; 15: 1782-1789.

33. Pfister DG, Johnson DH, Azzoli CG, et al. American Society of Clinical Oncology treatment of unresectable non-small-cell lung cancer guideline: update 2003. I Clin Oncol 2004; 22: 330-353.

34. Langer C), Manola J, Bernardo P, et al. Cisplatinbased therapy for elderly patients with advanced nonsmall-cell lung cancer: implications of Eastern Cooperative Oncology Group 5592, a randomized trial. J Natl Cancer Inst 2002; 94: 173-181.

35. Lilenbaum RC, Herndon JE 2nd, List MA, et al. Single-agent versus combination chemotherapy in advanced non-small-cell lung cancer: The Cancer and Leukemia Group B (study 9730). J Clin Oncol 2005; 23: 190-196.

36. Belani CP, Fossella F. Elderly subgroup analysis of a randomized phase III study of docetaxel plus platinum combinations versus vinorelbine plus cisplatin for first-line treatment of advanced nonsmall cell lung carcinoma (TAX 326). Cancer 2005; 104: 2766-2774.

37. Ansari RH, Socinski MA, Edelman MJ, et al. A retrospective analysis of outcomes by age in a three-arm phase III trial of gemcitabine in combination with carboplatin or paclitaxel versus paclitaxel plus carboplatin for advanced non-small cell lung cancer. Crit Rev Oncol Hematol 2011; 78: 162-171.
38. Blanchard EM, Moon J, Hesketh PJ, et al. Comparison of platinum-based chemotherapy in patients older and younger than 70 years: an analysis of Southwest Oncology Group Trials 9308 and 9509. J Thorac Oncol 2011; 6: 115-120.

39. Effects of vinorelbine on quality of life and survival of elderly patients with advanced non-small-cell lung cancer. The Elderly Lung Cancer Vinorelbine Italian Study Group. J Natl Cancer Inst 1999; 91: 66-72.

40. Frasci G, Lorusso V, Panza N, et al. Gemcitabine plus vinorelbine versus vinorelbine alone in elderly patients with advanced non-small-cell lung cancer. J Clin Oncol 2000; 18: 2529-2536.

41. Gridelli C, Perrone F, Gallo C, et al. Chemotherapy for elderly patients with advanced non-small-cell lung cancer: the Multicenter Italian Lung Cancer in the Elderly Study (MILES) phase III randomized trial. J Natl Cancer Inst 2003; 95: 362-372.

42. Pallis AG, Gridelli C, van Meerbeeck JP, et al. EORTC Elderly Task Force and Lung Cancer Group and International Society for Geriatric Oncology (SIOG) experts' opinion for the treatment of non-small-cell lung cancer in an elderly population. Ann Oncol 2010; 21: 692-706.

43. Kudoh S, Takeda K, Nakagawa K, et al. Phase III study of docetaxel compared with vinorelbine in elderly patients with advanced non-small-cell lung cancer: results of the West Japan Thoracic Oncology Group Trial (WJTOG 9904). J Clin Oncol 2006; 24: 3657-3663.

44. Tsukada H, Yokoyama A, Nishiwaki Y. Randomized controlled trial comparing docetaxel-cisplatin combination with docetaxel alone in elderly patients with advanced nonsmall cell lungcancer. I Clin Oncol 2007; 25: 18s, 7629 .

45. Quoix E, Zalcman G, Oster JP, et al. Carboplatin and weekly paclitaxel doublet chemotherapy compared with monotherapy in elderly patients with advanced non-small cell lung cancer. IFCT 0501 randomized phase 3 trial. Lancet 2011; 378: 1079-1088. 